\title{
Opsoclonus myoclonus syndrome in a patient with Japanese encephalitis: a case report
}

\author{
Subatharshini Sountharalingam ${ }^{1}$, H. M. M. T. B. Herath ${ }^{1 *}$, Dharshana Wijegunasinghe ${ }^{2}$ and Sunethra Senanayke ${ }^{2}$
}

\begin{abstract}
Background: Opsoclonus myoclonus syndrome is a rare neurological disorder that usually manifests as a paraneoplastic phenomenon. Although some viruses are reported to cause this condition, opsoclonus myoclonus syndrome by Japanese encephalitis has not been reported previously.

Case presentation: Here we present the case of a 31-year-old Sri Lankan woman who presented with fever, altered level of consciousness, opsoclonus, and facial myoclonus. She was diagnosed as having Japanese encephalitis based on cerebrospinal fluid and serum Japanese encephalitis-specific immunoglobulin $\mathrm{M}$ antibody and characteristic magnetic resonance imaging abnormalities. She was given intravenously administered methylprednisolone pulses (1000 mg per day) for 5 days. With this she improved gradually with reduction in opsoclonus and myoclonic movements. Her limb muscle power and speech also improved slowly.

Conclusions: We intended to highlight the fact that opsoclonus myoclonus syndrome can be a feature of infection with Japanese encephalitis and that it can be added to the list of viruses which cause opsoclonus. Currently there is no well-accepted treatment for opsoclonus myoclonus syndrome and intravenously administered methylprednisolone pulses and immunosuppressants can be used successfully in these patients for early recovery.
\end{abstract}

Keywords: Japanese encephalitis, Opsoclonus myoclonus syndrome

\section{Background}

Japanese encephalitis (JE) is a mosquito-borne viral encephalitis caused by a Flavivirus closely related to West Nile and St. Louis encephalitis viruses [1]. Humans are an incidental dead-end host while pigs and birds are the amplifying hosts. The culicine mosquito species Culex tritaeniorhynchus and Culex gelidus are the principal vectors. However, some other culicine mosquito species such as Culex vishnui, Culex pseudovishnui, and Culex fuscocephala are also responsible for the transfer of the virus to humans from amplifying hosts $[1,2]$. A majority of infections are asymptomatic and only less than $1 \%$ manifest as encephalitis [1]. Nearly 35,000 to 50,000 cases of JE are reported to the World Health Organization (WHO) each year, resulting in an estimated 10,000 to 15,000 deaths annually. The case fatality rate varies between 5 and 30\%,

\footnotetext{
* Correspondence: Tharukaherath11@gmail.com

${ }^{1}$ Medical Department, National Hospital of Sri Lanka, Colombo, Sri Lanka Full list of author information is available at the end of the article
}

while 30 to $50 \%$ of survivors have significant neurological sequelae [1].

The clinical course is divided into prodromal phase, acute encephalitic stage, and late phase. The prodromal phase starts before the onset of encephalitis, with fever and constitutional symptoms. Altered sensorium, nuchal rigidity, and abnormal movements characterize the encephalitic stage. Recovery or persistence of central nervous system signs occurs in the late phase [1]. Cases of opsoclonus myoclonus syndrome (OMS) caused by JE have not been reported previously. Here we discuss a patient with JE who presented with OMS.

\section{Case presentation}

A 31-year-old previously healthy Sri Lankan woman from southern parts of Sri Lanka presented with fever for 3 days and altered level of consciousness for 1 day. The fever was associated with headache and myalgia and she did not have nausea, vomiting, or skin rashes. On admission to our hospital she was afebrile and nuchal rigidity was present. She 
was conscious but aphasic. Her Glasgow Coma Scale was 11/15 (E 4, V 1, M 6). There were involuntary conjugate fast eye movements in all the directions of gaze without a saccadic interval, suggestive of opsoclonus. There were no ophthalmoplegia or other cranial nerve palsies. Her pupils were equally reacting to light. Fundoscopy revealed papilledema. There were involuntary twitching movements on the right side of her face, mandible, and tongue, which increased with movement and disappeared during sleep. Both upper and lower limb tone were normal and she was able to move her limbs against gravity, but not against resistance (power 3/5). The deep tendon reflexes were present. Bilateral plantar responses were flexor. Her other vital signs were stable with a heart rate of 68 beats per minute (bpm), blood pressure of $130 / 80 \mathrm{mmHg}$, and blood oxygen saturation $\left(\mathrm{spO}_{2}\right)$ on air was $96 \%$. All other system examinations were unremarkable.

Her full blood count revealed a neutrophil leukocytosis: white blood cells, $14 \times 10^{3} / \mu \mathrm{L}$; neutrophills $(\mathrm{N})$, $78 \%$; lymphocytes (L), 11\%; eosinophills (E), 02\%; basophills (B), 5\%; platelets, $280 \times 10^{3} / \mu \mathrm{L}$; and hemoglobin, $13 \mathrm{~g} / \mathrm{dl}$. Her erythrocyte sedimentation rate was $66 \mathrm{~mm}$ in the first hour but her C-reactive protein was less than $6 \mathrm{mg} / \mathrm{dl}$. Her serum electrolytes and renal and liver profiles were normal: sodium (Na), $133 \mathrm{mmol} / \mathrm{l}$; potassium (K), $4.5 \mathrm{mmol} / \mathrm{l}$; serum calcium, $2.3 \mathrm{mmol} / \mathrm{l}$; magnesium, $0.99 \mathrm{mmol} / \mathrm{l}$; aspartate aminotransferase (AST), $40 \mathrm{U} / \mathrm{l}$; and alanine aminotransferase (ALT), $47 \mathrm{U} / \mathrm{l}$. Her thyroid stimulating hormone was $0.34 \mathrm{IU} / \mathrm{L}$. Blood and urine culture, blood film for malaria parasite, rheumatoid factor, antinuclear antibody, and human immunodeficiency virus serology were negative. Thyroid microsomal antibody was less than $10 \mathrm{IU} / \mathrm{ml}$ and $\mathrm{N}$-methyl-D-aspartate (NMDA) receptor antibody was also negative. A non-contrast computed tomography of her brain showed cerebral edema. Cerebrospinal fluid (CSF) opening pressure was $180 \mathrm{mmH}_{2} \mathrm{O}$ and full report showed high level of proteins of $130 \mathrm{mg} / \mathrm{dl}$ with 60 lymphocytes/ $\mathrm{mm}^{3}$. Polymorphs and red blood cells were absent in CSF. CSF glucose was $3.4 \mathrm{mmol} / \mathrm{l}$ (corresponding random blood sugar was $5.5 \mathrm{mmol} / \mathrm{l})$. Herpes simplex virus polymerase chain reaction in CSF was negative. IgM for JE became positive in both serum and CSF. Magnetic resonance imaging (MRI) of her brain showed symmetrical bilateral high signal intensities in basal ganglia, head of the caudate, and

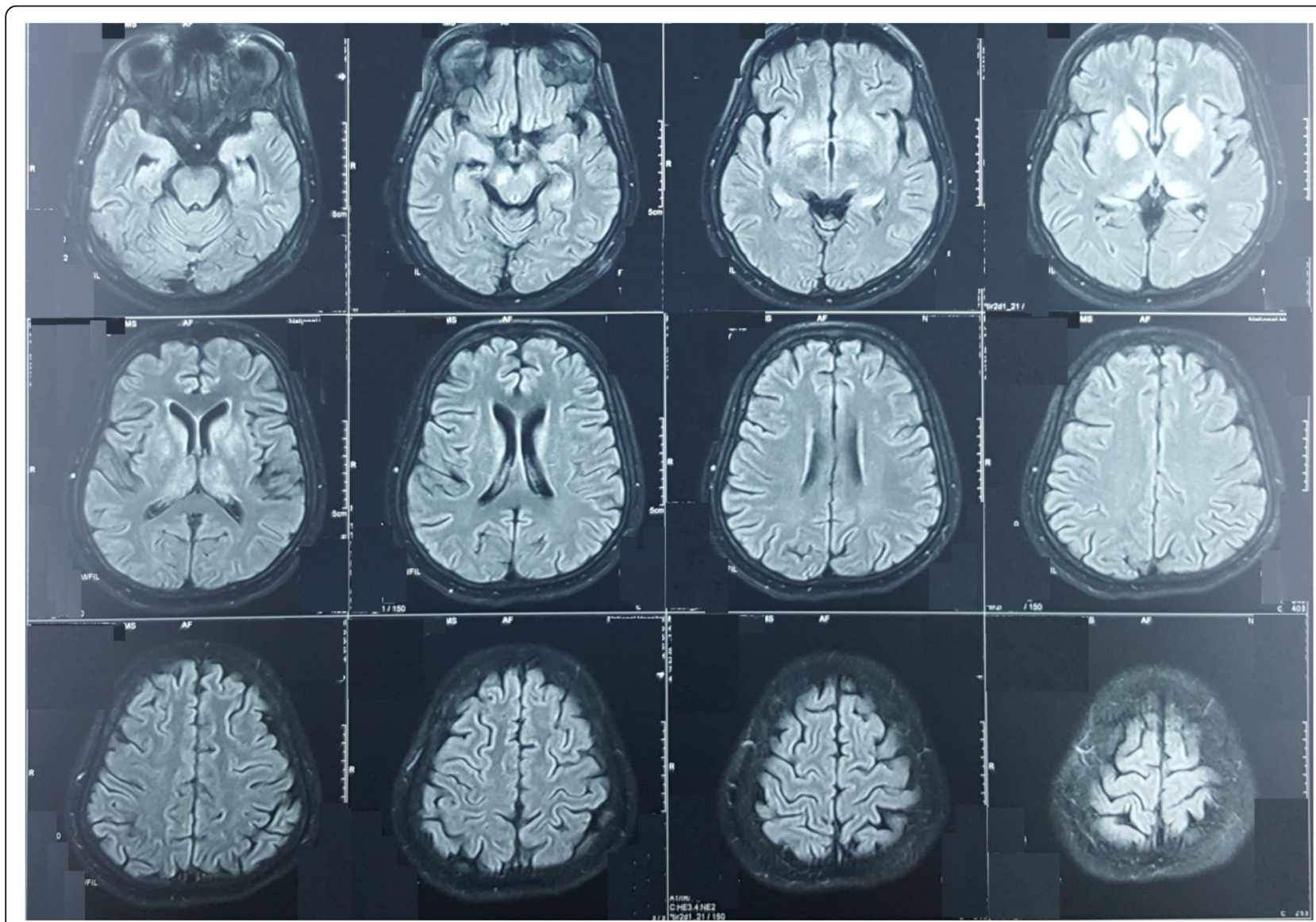

Fig. 1 Magnetic resonance imaging of the patient's brain showing symmetrical bilateral high signal intensities in basal ganglia, caudate head, and midbrain in fluid-attenuated inversion recovery 
midbrain in T2 and fluid-attenuated inversion recovery (FLAIR) without diffusion restriction (Fig. 1). Serial electroencephalograms (EEGs) were done which showed various epileptiform discharges. Initial EEG showed bilateral periodic lateralized epileptiform discharges (Fig. 2) and the second EEG after 2 days showed left-sided lateralization with background slowing.

She was given supportive care and once JE was confirmed we administered methylprednisolone pulses intravenously (1000 mg per day) for 5 days. With this, she improved gradually with reduction in opsoclonus and myoclonic movements. Her limb muscle power and speech also improved slowly. After approximately 2 weeks of the disease duration, epileptic discharges and background slowing in an EEG showed improvement. During the course of her illness she became rigid and a quarter of a tablet of levodopacarbidopa (250/25 mg) was started at a frequency of three times a day to alleviate the extrapyramidal symptoms.

\section{Discussion}

Viral encephalitis classically causes fever, headache, altered sensorium, neuropsychiatric manifestations, catatonia, and abnormal movements such as orolingual tremors, myokymia, and lip smacking, and mandibulo-faciolingual tremors are also reported [3, 4]. Even though OMS is not commonly caused by infections, there are case reports of viral encephalitis which had caused OMS such as varicella zoster, West Nile encephalitis [5], and mumps [6]. OMS after influenza vaccination was also reported [7] and in India OMS due to malaria had been reported [8].

OMS also known as myoclonic encephalopathy (Kinsbourne syndrome) and "dancing eyes-dancing feet syndrome", is a rare neurological disorder that occurs at a prevalence of 1 in 10,000,000. It usually occurs in children with neuroblastoma as a paraneoplastic manifestation and in adults due to underlying lung cancer and gynecological malignancies. Toxins and autoimmune diseases like Hashimoto encephalopathy are known to cause OMS as well [9]. Opsoclonus is defined as chaotic, conjugate, multivector, back-to-back, saccadic eye movements without intersaccadic latency. It is also called saccadomania [9]. It is thought to occur due to damage of the omnipause cells in the pontine raphe nucleus [9]. Our patient had opsoclonus and involuntary twitching

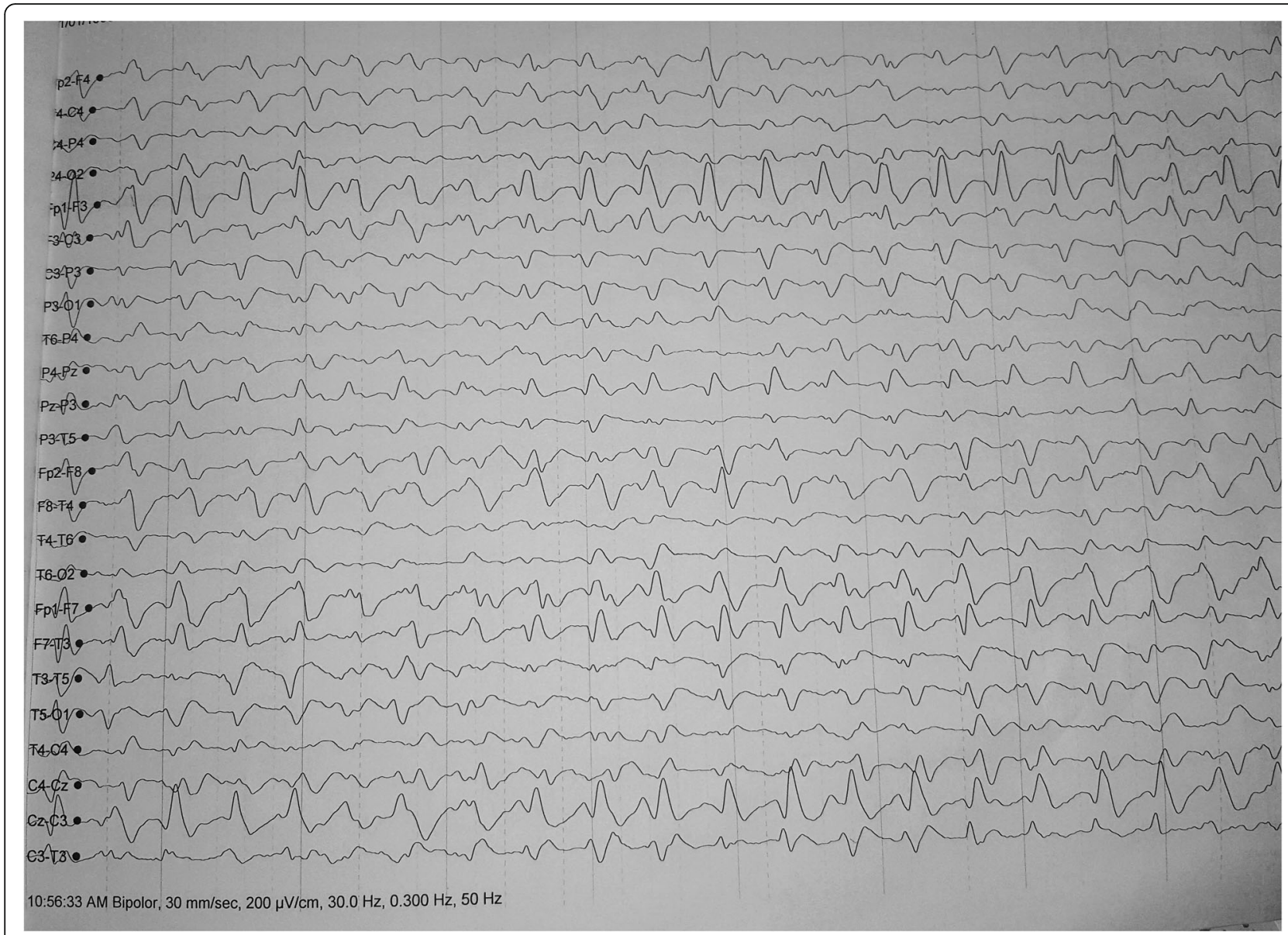

Fig. 2 Electroencephalogram showing bilateral periodic lateralized epileptiform discharges 
movements of the right side of her face suggestive of myoclonus. Ataxia and cerebellar involvement could not be assessed in our patient.

Diagnosis of JE depends on imaging and CSF analysis. Characteristic MRI appearance is T2 and FLAIR hyperintensities in thalamus, basal ganglia, caudate, and midbrain bilaterally. Although CSF pressure is elevated in approximately $50 \%$ of cases, it was normal in our patient. A CSF full report showed elevated protein with CSF lymphocytosis typical of JE. JE-specific IgM antibody was positive in CSF as well as in serum in the second week of illness. Ultrasound imaging of her abdomen and a chest X-ray that were done to exclude underlying malignancies were normal. Hashimoto encephalopathy and autoimmune encephalitis also can cause a similar clinical picture but thyroid peroxidase antibody and NMDA receptor antibody were negative in our patient.

Various therapies have been tried successfully in patients with OMS and they include corticosteroids, intravenously administered immunoglobulin, immunosuppressants, plasma exchange, rituximab, adrenocorticotropic hormone $(\mathrm{ACTH})$, and clonazepam. In our case, a significant improvement was observed with intravenously administered methylprednisolone pulses over a short period of time. Parkinsonism features improved dramatically after a small dose of levodopa-carbidopa.

\section{Conclusions}

We intended to highlight that OMS can also be a feature of JE and that this virus can be added to the list of viruses that can cause OMS. Currently there is no well-accepted treatment in OMS and intravenously administered methylprednisolone pulses and immunosuppressants can be used successfully in these patients for early recovery.

\begin{abstract}
Abbreviations
ACTH: Adrenocorticotropic hormone; ALT: Alanine aminotransferase; AST: Aspartate aminotransferase; bpm: Beats per minute; CSF: Cerebrospinal fluid; EEG: Electroencephalogram; FLAIR: Fluid-attenuated inversion recovery; JE: Japanese encephalitis; K: Potassium; MRI: Magnetic resonance imaging; Na: Sodium; NMDA: N-methyl-D-aspartate; OMS: Opsoclonus myoclonus syndrome; $\mathrm{SpO}_{2}$ : Blood oxygen saturation; WHO: World Health Organization
\end{abstract}

\section{Acknowledgements}

This case report was supported by doctors working in Ward 16, National Hospital of Sri Lanka, in acquisition, analysis, and interpretation of data. We are thankful to the patients' relatives for the support given in providing data.

Funding

No source of funding.

\section{Availability of data and materials}

The datasets supporting the conclusions of this article are included within the article.

\section{Authors' contributions}

All authors were involved in the management of the patient. SSo wrote the first draft. HMMTBH, SSe, and DW revised it. All authors have read and approved the final manuscript.
Ethics approval and consent to participate

Not applicable.

\section{Consent for publication}

Written informed consent was obtained from the patient for publication of this case report and any accompanying images. A copy of the written consent is available for review by the Editor-in-Chief of this journal.

\section{Competing interests}

The authors declare that they have no competing interests.

\section{Publisher's Note}

Springer Nature remains neutral with regard to jurisdictional claims in published maps and institutional affiliations.

\section{Author details}

${ }^{1}$ Medical Department, National Hospital of Sri Lanka, Colombo, Sri Lanka. ${ }^{2}$ Neurology Department, National Hospital of Sri Lanka, Colombo, Sri Lanka.

Received: 6 July 2017 Accepted: 13 September 2017

Published online: 23 October 2017

\section{References}

1. Wijesinghe P. Japanese Encephalitis: A Manual for Medical Officers. Sri Lanka: Epidemiology Unit; 2008.

2. Wang H, Liang G. Epidemiology of Japanese encephalitis: Past, present, and future prospects. Ther Clin Risk Manag. 2015;11:435-48.

3. Misra UK, Kalita J. Prognosis of Japanese encephalitis patients with dystonia compared to those with parkinsonian features only. Postgrad Med J. 2002; 78:238-41. doi:10.1136/pmj.78.918.238.

4. Deshpande A, Khardenavis S, Shetty A. Case report of patient with orolingual tremors as post Japanese encephalitis sequelae. Med J Dr DY Patil Univ. 2014;7:766. doi:10.4103/0975-2870.144874.

5. Birlutiu V, Birlutiu RM. Opsoclonus-myoclonus syndrome attributable to West Nile encephalitis: a case report. J Med Case Rep. 2014;8:232.

6. Kang B, Kim J. Opsoclonus-Myoclonus Syndrome Associated with Mumps Virus Infection. J Clin Neurol. 2014;10:272-5.

7. Groiss SJ, Siebler M, Schnitzler A. Full recovery of adult onset opsoclonus myoclonus syndrome after early immunotherapy: A case report. Mov Disord. 2011;26:1805-7.

8. Bose K, Saha S, Islam MR, Chakraborty C, Laskar M. Opsoclonus myoclonus ataxia syndrome due to falciparum malaria in two Indian children. Indian J Ophthalmol. 2016;64:852-4. doi:10.4103/0301-4738.195611.

9. Pranzatelli MR. The Neurobiology of the Opsoclonus-Myoclonus Syndrome. Clin Neuropharmacol. 1992;15(3):186-228.

Submit your next manuscript to BioMed Central and we will help you at every step:

- We accept pre-submission inquiries

- Our selector tool helps you to find the most relevant journal

- We provide round the clock customer support

- Convenient online submission

- Thorough peer review

- Inclusion in PubMed and all major indexing services

- Maximum visibility for your research

Submit your manuscript at www.biomedcentral.com/submit
C Biomed Central 